
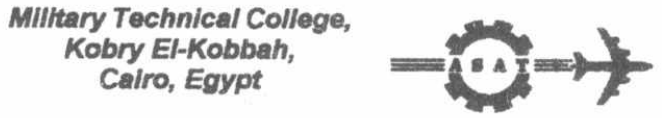

$9^{\text {th }}$ International Conference

On Aerospace Sciences \&

Aviation Technology

\title{
USE OF LOCAL MATERIALS FOR CONSTRUCTION OF ANTINUCLEAR AIRPLANE SHELTERS (MECHANICAL PROPERTIES)
}

N.A. El-Sharara*, M.A. Mousa*, M.M. El-Dessouky* and A.M.I. Knay **

\begin{abstract}
Heavy weight concrete is used for construction of shelters to provide protection against blast effects of nuclear bursts. In this study IImenite is used as coarse aggregate, serpentine is used as fine aggregate and normal Portland cement. Different concrete mixes were designed, produced, cured and tested for compressive, tensile, flexural strengths, ultrasonic and bulk weight. Admixtures were employed to improve the mechanical properties. The results showed that the ilmenite-serpentine heavy weight concrete (ISHWC) has good mechnaical properties for construction of antinuclear shelters.
\end{abstract}

Key Word: Shelters, Heavy weight concrete, Nuclear bursts.

* Egyptian Armed Forces

** Al-Azhar University, Faculty of Science, Cairo, Egypt 


\section{Introduction}

Different types of concrete are commonly used for shieidirig of military structures and is frequently dequary weight concrete of sufficient thickners can be used. However, it the shield size, and thus make use of heavy weight concrete to permit reduction of produced by the use be protect against the effects af building or aggregate effects of nuclear blast. The IS.HWC can be fabricated by as by conventional mixingersion, grout intrusion or prepacked construction, as well of an extensive la mixing and placing methods. In this study, results are represented mechanical properties of work which has performed to investigate the structural and mechanical properties of concrete shield of unit weigh't in the range of $3.00-3.47$

Scope of the test program

The scope of the work deais with an experimental investigation to study the properties of heavy weight concrete, some important parameters such as aggregates gradation, ratio between fine and coarse aggregate, cernent content, water content and plasticizing additives.

The scope of test program is shown in Fig.1. The concrete mixes were designed to [1].

\section{Experimental Work}

The material used were irmenite (Iron titanium oxides) as coarse aggregate, and serpentine (Hydrous magnessium silicate) as fine aggregate. Plasticizing material are used to achieving the desired slump with less water at a constant cement content to improve the strength and durability. The factors that can affect the strength of concrete can be classififad into four categories: constituent materials, method of preparation, curing procedures, and test conditions. Thus, the research will be concerned primarily with the effects of the concrete constituents, cement content, aggregates and water on the mechanical properties of ISHWC. The samples are tested at 7 and 28 days. It is found that the specific gravity for ilmenite is 4.00 and for serpentine is 2.6 .

\section{Compressive strength test}

The compressive strength of concrete is one of the most important technical properties. In most structural applications, concrete is employed primarily to resists compressive strength stresses. It is usually determiried by submitting a specimen of constant cross section to a uniformly distributed incr easing axial compression load in a suitable testing machine until failure occurs. The maximum load and type of failure are then reported [2].

Tensile strength test

Since concrete is a hetrogeneous material, it is relatively weak in tension. The tensile strength is about orie-tenth of the compressive strength in early ages (7-days) and 
about one-eirhth of the compressive strength in later ages (28-days). The indirect tension (split) test is carried out on standard cylinders to determine the tensile strength of concrete [3].

\section{Flexural strength test}

The other way of estimating the tensile strength of concrete is by flexural test (ASTM C-78). The specimens are formed as beams $10 \times 10 \times 50 \mathrm{Cm}$. The beams are cured in the standard manner and are then tested in one third-point loading test [2]. The flexural strength of high strength is about $10 \%$ of its compressive strength.

\section{Ultrasonic pulse velocity test}

This method is based on the pulse velocity through a known thickness of concrete, using the procedures outlined in ASTMC 597 [2]. The pulse velocity is used directly as a quality control measure, but more commonly it is overlated with strength. The pulse velocity is used to study uniformity, estimation of strength, setting characteristics, durability and the extent of cracking in concrete, as well as the modulus of elasticity.

\section{Results and Discussion}

\section{Properties of fresh ISHWC}

The amount of the used mixing water differed according to the proportions. In all cases the water cement ratio was selected to give a slump of $3-5 \mathrm{~cm}$. Variation of water-cement ratio for different concrete mixes are shown in Table 1.

\section{Compressive strength}

For all cement content and fine aggregate percentages, the compressive strength of ISHWC increased by time. The specimens were tested at 7 and 28 days. Generally ISHWC behaves in a manner similar to the ordinary concrete bearing in mind the short period of testing. Compressive strength increases as cement content increases as shown in Fig. 2. Regarding the effect of plasticizer on the compressive strength, it has a contributing effect on the strength with both cement content 350 and 400 $\mathrm{Kg} / \mathrm{m}^{3}$. This valid for all ages and for $33 \%$ of fine aggregate as shown in Fig.3. The measured strength indicates an important phenomena regarding the influence of fine aggregate, as illustrated in Fig.4; the optimum fine aggregate percent was $33 \%$. Each of the figure indicates that the compressive strength increases as fine aggregate content increases for cement content $350 \mathrm{Kg} / \mathrm{m}^{3}$. But that is not valid for $50 \%$ of fine aggregate, where the strength decreases. The mode of failure of the cubes was the common shape.

\section{Unit weight}

In this study the ISHWC unit weight ranged between $3-3.47 \mathrm{t} / \mathrm{m}^{3}$. These values are $120 \%$ and $138 \%$ of normal weight concrete. Generally the unit weight increases as the fine aggregate content decreases in the form of a percent of the total aggregate as shown in Fig.5. The unit weight increases with 325 and $350 \mathrm{Kg} / \mathrm{m}^{3}$, but for 400 cement content, unit weight decreases, as shown in Fig.6. The maximum unit weight of ISHWC was at a cement content of $350 \mathrm{Kg} / \mathrm{m}^{3}$. 


\section{Tensile strength}

The maximum tensile strength reaches $14.7 \mathrm{Kg} / \mathrm{cm}^{2}$ and occurs at $350 \mathrm{Kg} / \mathrm{m}^{3}$ cement content and $33 \%$ fine aggregate as shown in Fig.7. Regarding the effect of plasticizer, tensile strength reaches $15.5 \mathrm{Kg} / \mathrm{cm}^{2}$ and occurs at $400 \mathrm{Kg} / \mathrm{m}^{3}$ cement content and $33 \%$ fine aggregate, as shown in Fig. 8 . Results show that the tensile strength increases as the fine aggregate increases till $33 \%$ fine aggregate, but at $50 \%$ fine aggregate it is decreases as shown in Fig.9.

\section{Flexural strength}

The maximum flexural strength reaches $80.2 \mathrm{Kg} / \mathrm{cm}^{2}$ and occurs at $350 \mathrm{Kg} / \mathrm{m}^{3}$ cement content and $33 \%$ fine aggregates as shown in Fig. 10. Regarding the effect of plasticizer, flexural strength reaches $87.8 \mathrm{Kg} / \mathrm{cm}^{2}$ and occurs at $400 \mathrm{Kg} / \mathrm{m}^{3}$ cement content and $33 \%$ fine aggregate, as shown in Fig. 11. Results show that the flexural strength increases as the fine aggregate increases till 33\% fine aggregate, but at $50 \%$ fine aggregate it is decrease as shown in Fig. 12.

\section{UItrasonic test of ISHWC}

The results show that pulse velocity is decreased in all kinds of ISHW and ordinary concrete as well as the temperature of heating increased, that is due decrease in the moisture content of the concrete, and may be is due to extent of cracks in the samples. From the Fig. 13 we show that the type B of ISHWS consider the best among all other kinds of ISHWC and that may be due to presence of plasticizer material in the mix of the concrete which increase its elastic modulus

\section{Conclusion}

\section{i.}

The ithenite and serpentine ores can be used as coarse and fine aggregates for the production of heavy weight concrete (ISHWC) of unit weight $3.47 \mathrm{t} / \mathrm{m}^{3}$. The most important parameters influencing the unit weight are the fine aggregate and cement content. When the tensile or flexural strength is of concern for structural purposes, it should not be taken equal to a percentage of the compressive strength as normal practice with ordinary concrete. For the achievement of heaviest unit weight the concrete mix designed should stick as much as possible to the fine aggregate of the total aggregate ratio of about $20 \%$ in addition to the appropriate grading curve. Ordinary Portland cement content should not be more than $350 \mathrm{Kg} / \mathrm{m}^{3}$. Water-cement ratio which gives the fresh concrete a consistency sufficient for proper casting. A slump value of $3-5 \mathrm{cms}$ appears suitable in this respect.

\section{References}

[1] S. Mindess et ai., Concrete, Prentice-Hall, N.Y. 91981).

[2] A.M. Neville, Properties of Concrete, McGraw Hill, N.Y., (1982)

[3] A. Morsy, "An Investigation of Some Properties of Heavy Weight Concrete Mixes in Egypt", Cairo, Egypt, (1980) 


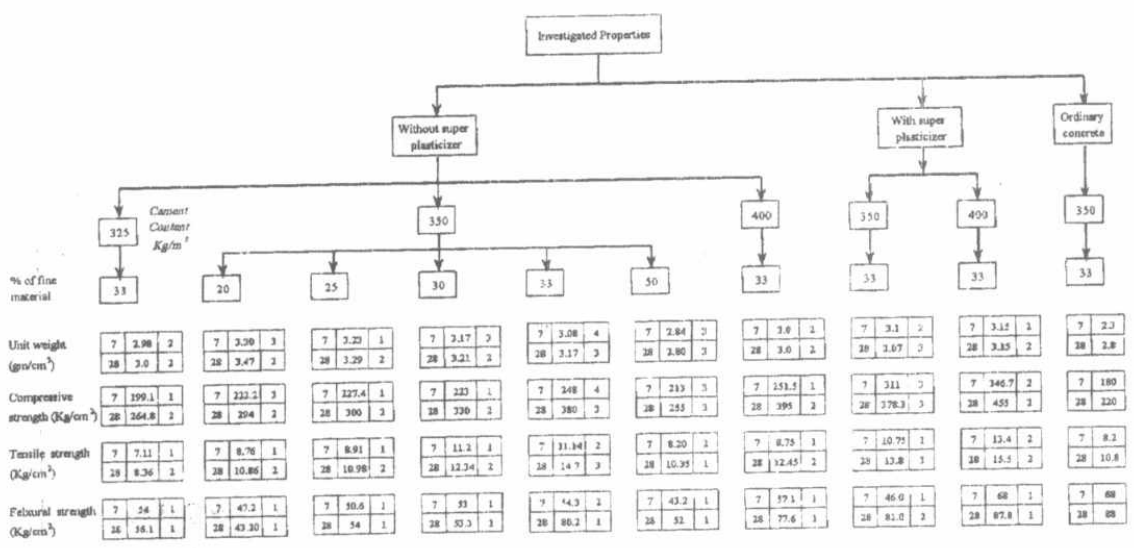

Fig.1 Investigated properties of ISHWC

Table 1 Variation of water-cement ratio for different concrete mixes

a) Mixes without using plasticizer

\begin{tabular}{|l|c|c|c|c|c|c|c|}
\hline Cement content $\mathrm{Kg} / \mathrm{m}^{3}$ & 325 & \multicolumn{7}{|c|}{350} & 400 \\
\hline$\%$ of fine material & 33 & 20 & 25 & 30 & 33 & 50 & 33 \\
\hline W/C ratio & 0.80 & 0.58 & 0.63 & 0.67 & 0.70 & 0.82 & 0.65 \\
\hline
\end{tabular}

b) Mixes with plasticizer

\begin{tabular}{|l|c|c|}
\hline Cement content $\mathrm{Kg} / \mathrm{m}^{3}$ & 350 & 400 \\
\hline$\%$ of fine material & 33 & 33 \\
\hline W/C ratio & 0.60 & 0.56 \\
\hline
\end{tabular}




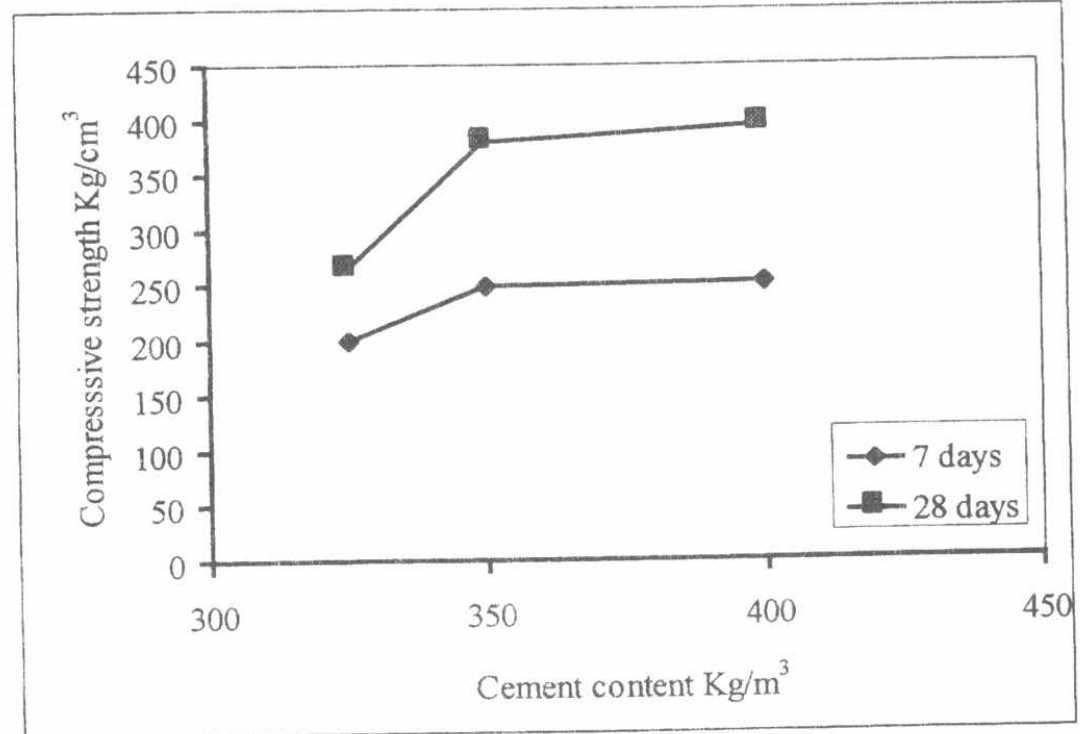

Fig. 2 Effect of cement content on the compressive strength at 7 and 28 age-days for $33 \%$ fine aggregate

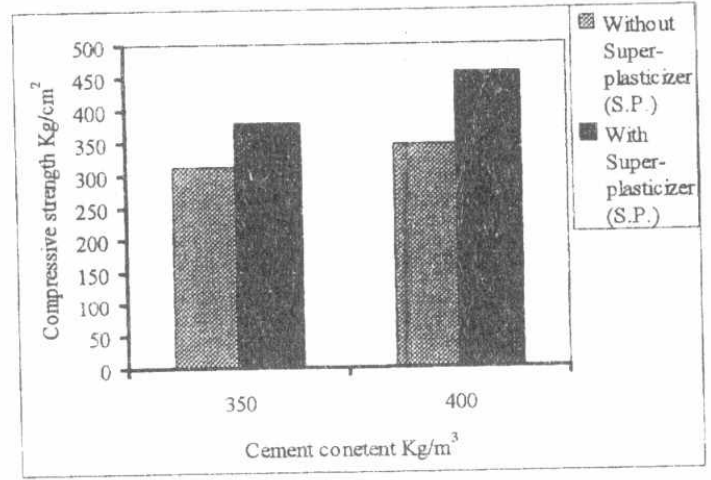

Fig.3 Effect of plasticizing material on the compressive strength of concrete at $33 \%$ fine aggregate content 


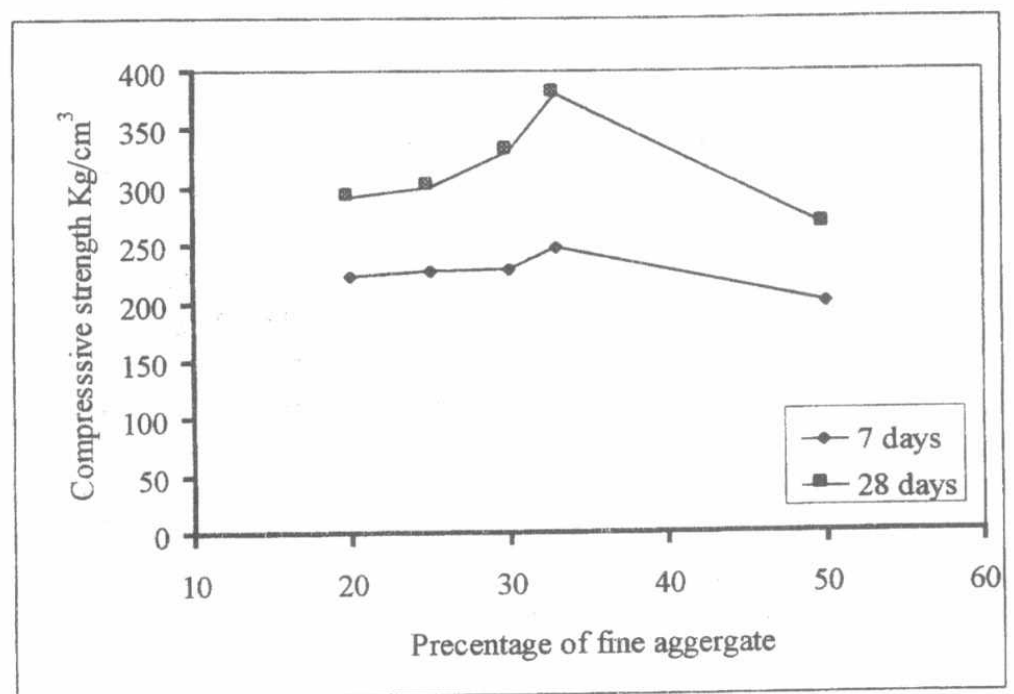

Fig.4 Effect of fine aggregate content on the compressive strength at 7 and 28 days

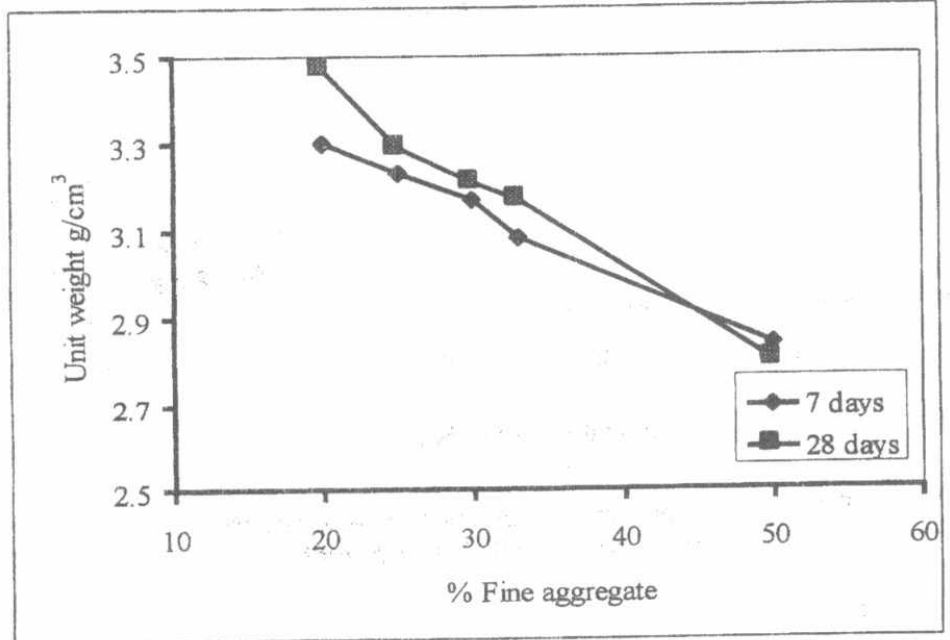

Fig.5 Unit weight as influenced by the fine aggregate content 


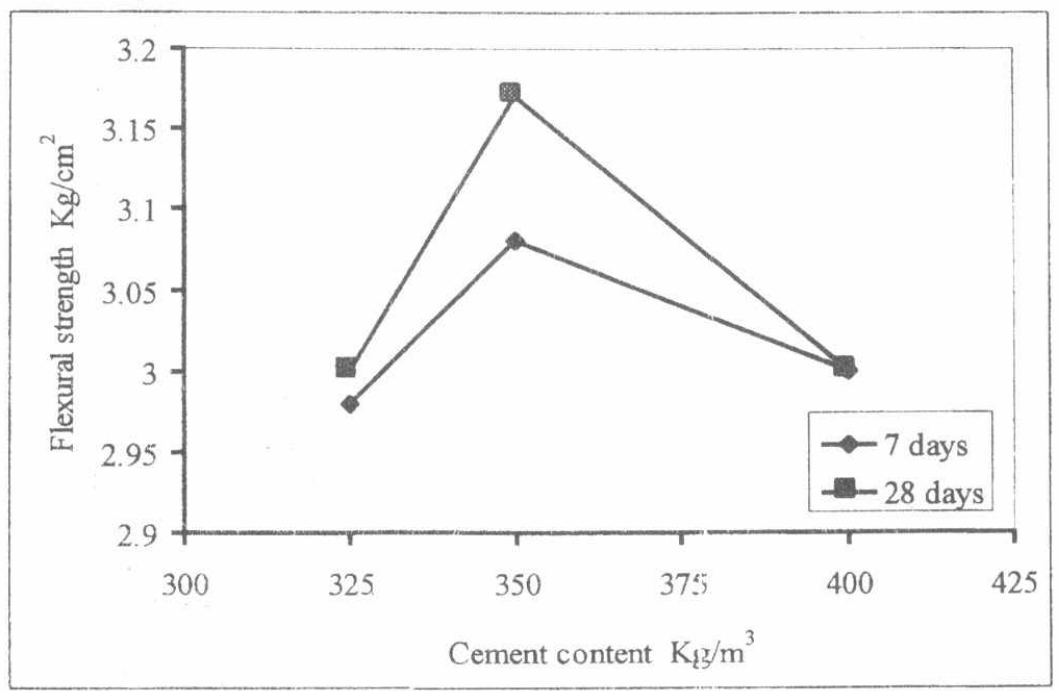

Fig.6 Effer:t of cement content on unit weight at $\bar{T}^{\prime}$ and 28 days at $33 \%$ f.agg

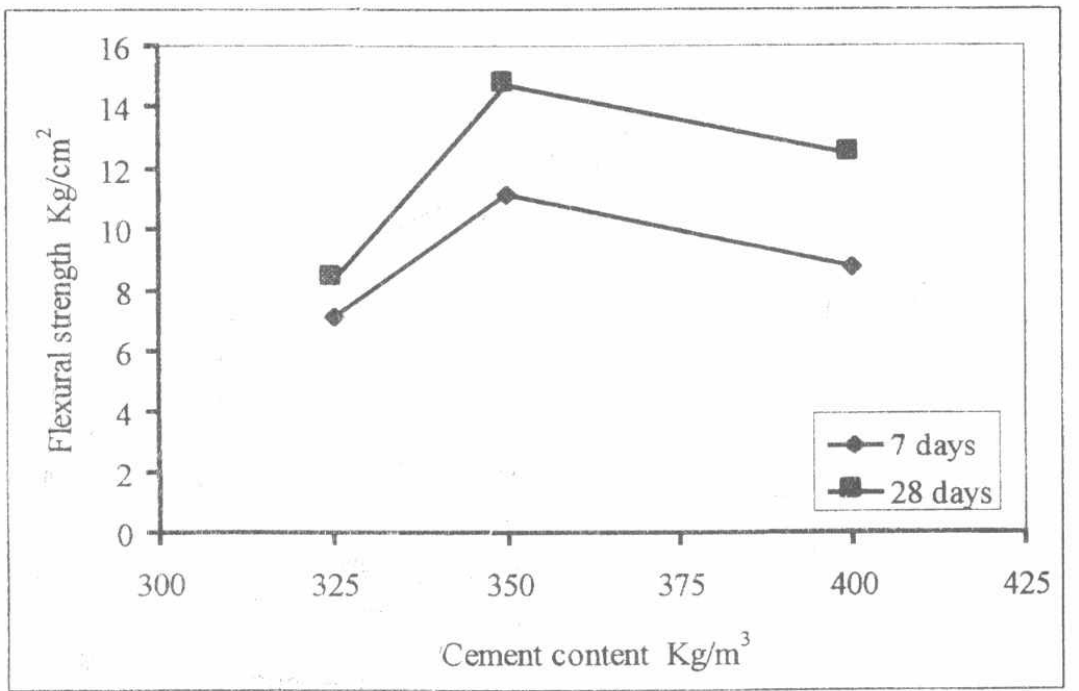

Fig.7 Effect of cement content on the tensile strength at 7 and 28 cdays and for $33 \%$ fine aggregate 


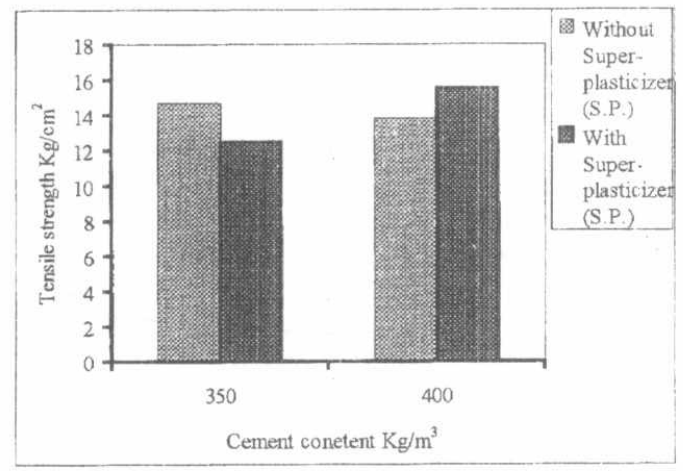

Fig. 8 Effect of plasticizing material on the tensile strength of concrete at $33 \%$ fine aggregate content.

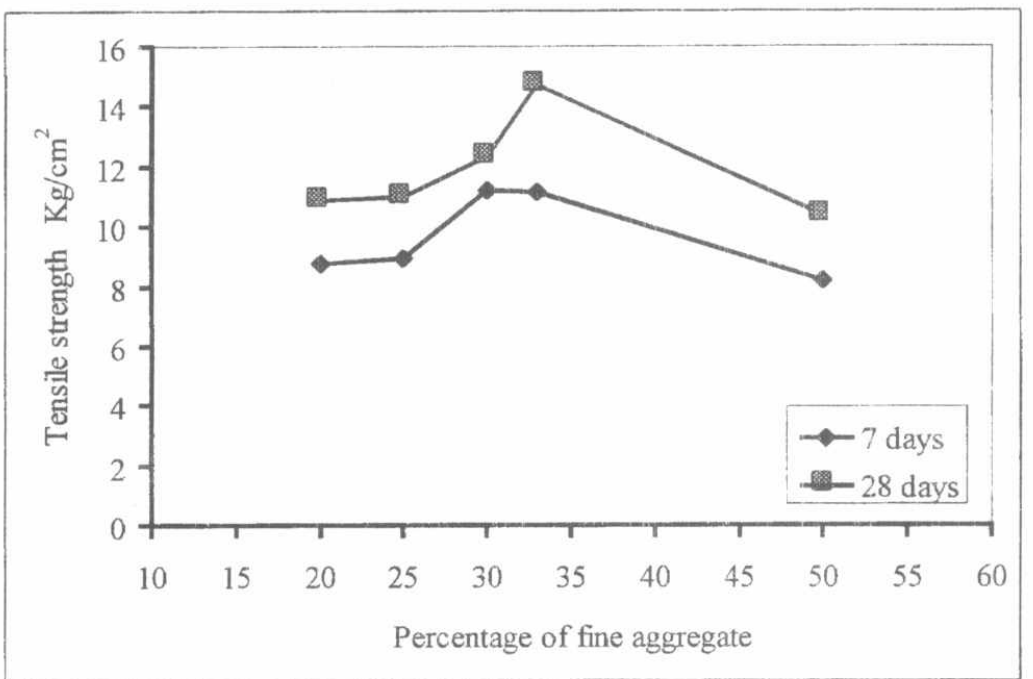

Fig.9 Effect of fine aggregate content on the tensile strength at 7 and 28 days 


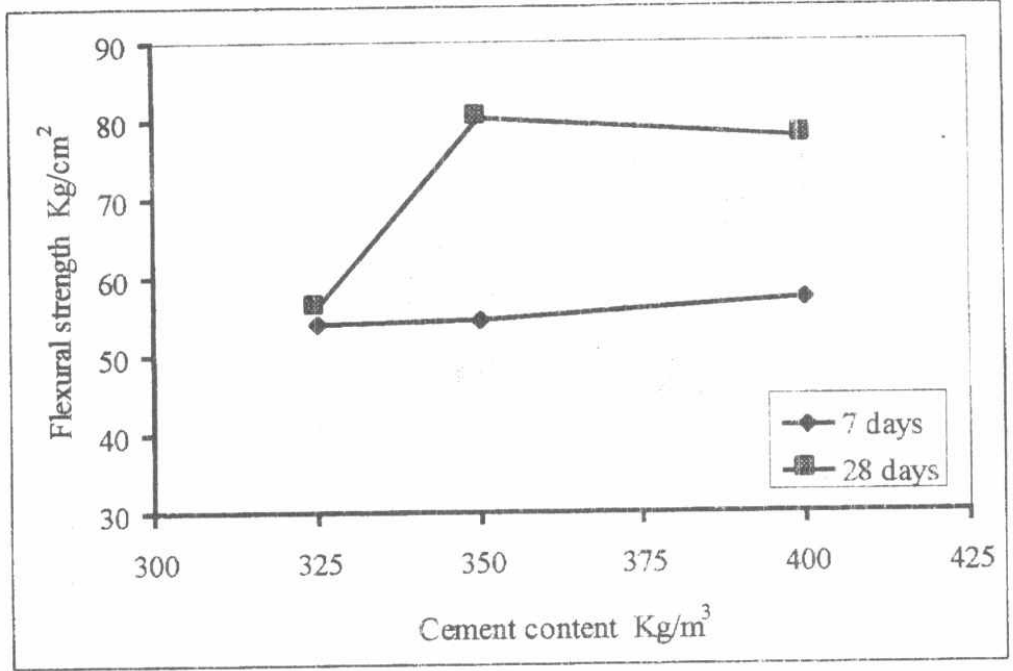

Fig.10 Effect of cement content on the felxural strength at 7 and 28 days and for $33 \%$ fine aggregate 


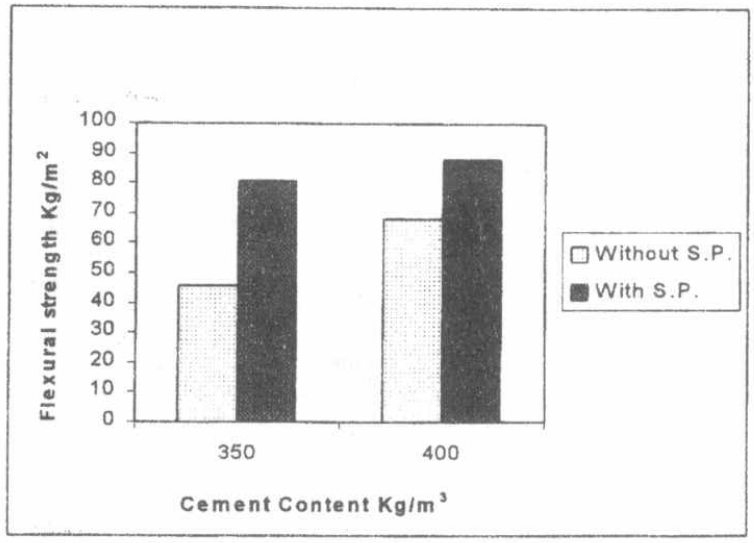

Fig.11 Effect of plasticizing material on the flexural of concrete at $33 \%$ fine aggregate content.

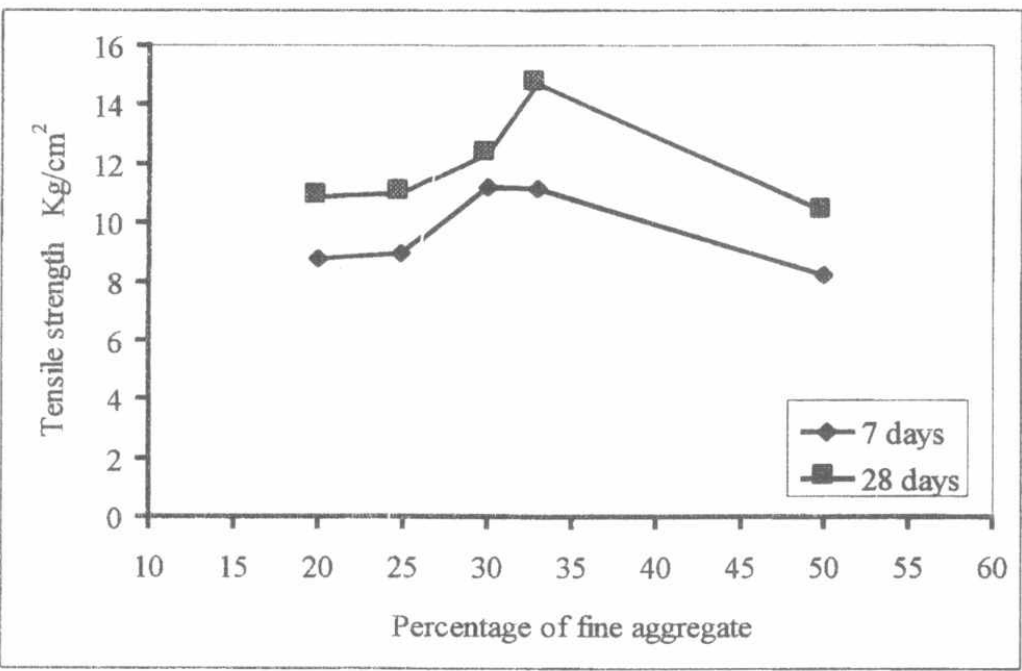

Fig.12 Effect of fine aggregate content on the tensile strength at 7 and 28 days 


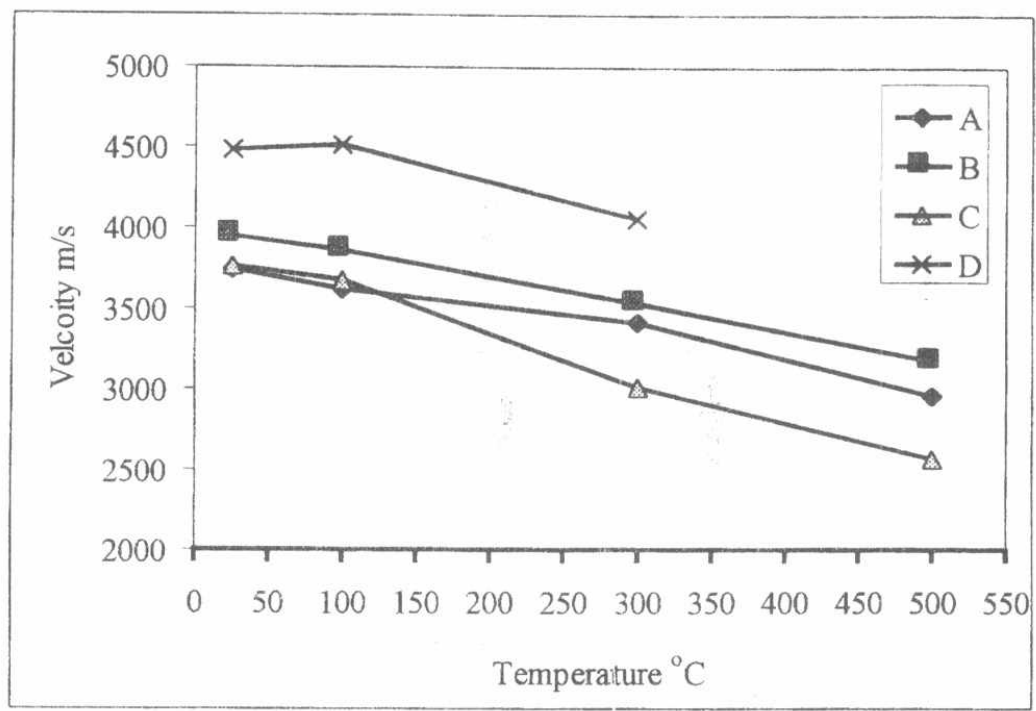

Fig.13 Ultrasound velocity measurements for different types of ISHWC 